\title{
Sobre naufragios y rescates: una historia social reciente sobre la ciencia en Argentina
}

\author{
On shipwrecks and rescues: \\ a recent social history of science in Argentina
}

\author{
María Silvia Di Liscia \\ Universidad Nacional de La Pampa, Argentina. \\ Santa Rosa - La Pampa - Argentina \\ silviadiliscia@gmail.com
}

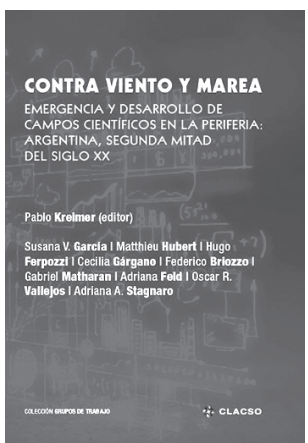

KREIMER, Pablo (Ed.).

Contra viento y marea: emergencia y desarrollo de campos científicos en la periferia: Argentina, segunda mitad del siglo XX. Buenos Aires: Clacso. 2016. 300p.
$\mathrm{C}^{\mathrm{s}}$ evidente, para lectores argentinos y latinoamericanos, Cla urgencia de este texto. En momentos donde sufren un vuelco significativo las políticas científicas de un ciclo dinámico (aunque problemático y cuestionado) y el futuro de gran parte de investigadores formados en la década pasada parece estar en jaque, un examen sobre los avances y retrocesos de los "campos científicos" en la modernidad periférica es refrescante y por qué no, aleccionador. A pesar que el pasado nunca permite repeticiones exactas, resulta siempre chocante el escaso o a veces nulo impacto de "las enseñanzas de la historia" en la planificación de las políticas públicas, y en el caso de las vinculadas a la ciencia y la tecnología, esa distancia es aún mayor.

Contra viento y marea (Kreimer, 2016) establece un ritmo y pautas claras sobre las esperanzas y frustraciones en la conformación y transformación de nuevos programas disciplinarios en el escenario nacional, como las ciencias del mar, la biología molecular, la genética

vegetal, la petroquímica, las nanociencias, la medicina nuclear y la informática. Se trata de un sólido ejercicio de historia social, centrado en la Argentina de la segunda mitad del siglo XX, cuando se conformó, maduró y luego se dispersó la expectativa del desarrollo científico-técnico que prometía tanto el progreso y la competitividad económica como el bienestar de la población. La elección de las temáticas del libro está en sintonía con la riqueza analítica de dicha mirada comparativa y crítica de los especialistas con las prácticas y productos científicos, atendiendo a los espacios sociales que rodean, permean y actúan sobre los investigadores.

Partiendo de una tradición historiográfica propia de la sociología constructivista, las interrogantes que sobrevuelan el texto, y que se exponen brillantemente, sobre todo en el capítulo introductorio del libro escrito por Pablo Kreimer, están en consonancia con el significado de la modernidad periférica en relación con los aportes científicos. Si bien se ha 
erosionado la noción de pensamiento racional, universal y neutral, la pregunta de cómo es la ciencia en los contextos no hegemónicos sigue siendo fecunda, eficaz y reconocida. Y esa pertinencia alcanza al presente, ya que la colonialidad del poder eurocéntrico del mainstream implica la asimetría de las conexiones entre científicos de diferentes márgenes y contextos así como de las formas de transmisión a través de las limitaciones lingüísticas, entre otros factores. Tales cuestiones inciden sobre los fenómenos socio-cognitivos, el espacio de la ciencia en las sociedades, las interrelaciones entre científicos y, en general, provocan un ejercicio de réplica y rutinización más que de innovación y originalidad en los resultados.

Atento a la significación general del texto, es importante indicar que no todos los capítulos desarrollan en igual sentido ni con similar profundidad el tratamiento analítico del campo en cuestión, situación que refiere tanto a los avances historiográficos sobre determinadas temáticas como a los niveles de análisis. Así, mientras que determinados aspectos resultan esbozados de manera profunda y con aportes singulares en un recorrido histórico significativo, otros construyen un relato descriptivo, aunque necesario, como aporte primario al desarrollo científico, circunscripto a determinadas décadas del siglo XX.

Una de las propuestas más sugerentes es la de Mathieu Hubert en relación a la emergencia de la nanociencia y nanotecnología, tanto vinculada a la revaloración simbólica de la enunciación de la especialidad como al rol estructurante de las políticas públicas. A través de un seguimiento de las cuatro redes formadas en el país, - que sin embargo, reactualizan las anteriores divisiones disciplinares entre física, química, biomedicina y ciencia de los materiales -, se pone a prueba la hipótesis de las divergencias notables entre el apoyo económico privado en los países post industrializados y en los que intentan ese camino, donde la ciencia y tecnología quedan bajo la responsabilidad estatal. El capítulo de Pablo Kreimer y de Hugo Ferpozzi sobre el desarrollo de la biología molecular avanza en un largo período (desde 1950 al presente), estructurando la historia interna de este campo disciplinar, desde su emergencia a su reconfiguración. A la vez que los autores examinan la enorme aplicación y la colonización de las prácticas de investigación de las ciencias de la vida (esperanzas a su vez no cumplidas en la aplicación de problemas médico-sociales de impacto nacional), se reflexiona sobre la permeabilidad del mundo académico y la incidencia de la represión política en las etapas de gobierno militar en un área científica, supuestamente lejana a las influencias ideológicas.

Igual situación se detecta en el capítulo de Cecilia Gárgano sobre la genética vegetal en Argentina en la era neoliberal. Este trabajo ya clásico en la historiografía nacional otorga elementos de prueba en relación a la investigación sobre el trigo, luego híbridos del maíz y posteriormente, la soja, en un contexto de ampliación de la frontera agrícola y de la postrevolución verde. Las consecuencias sociales de este proceso, que implican entre otras cuestiones el descenso de la ocupación laboral agrícola y concentración de la tierra, tuvieron también como correlato la apropiación de las empresas transnacionales de los registros de nuevos híbridos, fruto del esfuerzo de las agencias estatales de investigación.

La petroquímica, eje del capítulo de Gabriel Matharan y Adriana Feld, abarca la formación de una rama singular de la industria argentina vinculada a los combustibles, analizando la formación de grupos de investigadores en las universidades públicas y en el Consejo Nacional de Investigaciones Científicas y Técnicas (Conicet). La problemática energética 
significó un desarrollo estratégico de este sector, sostenido por los gobiernos democráticos y dictaduras de diferente signo ideológico pero consecuentes con una visión nacionalista del uso de los recursos no renovables. Tal como en los capítulos de Susana García sobre el interés científico en los mares argentinos o el frustrado desarrollo de la física, destacado por Federico Briozzo, la influencia de los militares sobrevuela la ciencia y la tecnología nacionales de manera notable; en ocasiones de forma francamente negativa porque produce el abandono de investigaciones y la pérdida de científicos. En otras ocasiones, los registros antisubversivos de los académicos de las universidades nacionales, perseguidos y obligados al exilio, introducen un vuelco curioso al financiamiento de otras determinadas agencias nacionales, como indican Matharan y Feld.

Es preciso destacar que el libro no ciñe - como en muchas otras historias argentinas - la denominación del espacio argentino a los centros porteños de investigación ni al análisis histórico o sociológico. La riqueza de esta obra también se demuestra al incluir las experiencias de nuevos campos científicos en provincias del litoral, como en el caso del capítulo de Oscar R. Vallejos sobre el desarrollo de la informática, en tanto dominio socioepistécnico. Así, se desarrolla el impulso de la industria y de las actividades científicas de la computación en la interrelación forjada entre el nivel internacional, el contexto nacional y los casos provinciales (Santa Fe y Buenos Aires). Tal es el sentido también del capítulo de Adriana Stagnaro, quien analiza la cultura científica de los años noventa a través de un trabajo comparativo, realizado en laboratorios privados y públicos de diferentes regiones argentinas y con la aplicación de una metodología etnológica.

Finalmente, el texto historia las áreas más protegidas de la ciencia argentina como nuevos campos emergentes, sin los panegíricos y las peripecias en pos del progreso del conocimiento sufrido por los héroes de bata y microscopio. Sin embargo, la construcción de la ciencia en Latinoamérica se hace contra viento y marea: las circunstancias políticas adversas, el financiamiento escaso o mal distribuido y, también, un contexto internacional desfavorable para el desarrollo autónomo. Este texto, de gran amplitud temática y cronológica, es también un rescate de ciertas políticas; y está abierto para los historiadores y para los estudiosos de la ciencia, interesados tanto en sus magnitudes, tendencias y propuestas como en las dificultades que conspiran para trastocarla y hacerla naufragar.

\section{REFERENCIA}

KREIMER, Pablo (Ed.).

Contra viento y marea: emergencia y desarrollo de campos científicos en la periferia: Argentina, segunda mitad del siglo XX. Buenos Aires: Clacso. 2016.

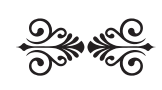

